\title{
Espacialidades
}

\section{O COMBATE À LEPRA NO RIO GRANDE DO NORTE:}

\section{a construção do Leprosário São Francisco de Assis durante as primeiras décadas do século XX}

The fight against leprosy in Rio Grande do Norte: the construction of the leprosarium São Francisco de Assis during the first decades of the twenty century.

Isa Cristina Barbosa Antunes ${ }^{1}$

Artigo recebido em: 23/07/2020. Artigo aceito em: 19/01/2021.

\section{RESUMO:}

O presente artigo discute como ocorreu a construção do Leprosário São Francisco de Assis, em Natal durante as duas primeiras décadas do século XX. Objetivamos analisar os debates médicos travados sobre a enfermidade, observando como eles influenciaram a construção do leprosário potiguar, e dissertar como ocorreu a edificação do isolamento. Utilizaremos os discursos dos membros da Comissão de Profilaxia da Lepra veiculados na revista Brazil-Médico, as mensagens dos Presidentes de Estado retratadas na Assembleia Legislativa do Rio Grande do Norte e os principais jornais que circulavam na cidade. Baseamos nossa análise nas ideias de espaço de Certeau, assim, entendemos o leprosário como um espaço construído que ganhou significado a partir dos discursos e dos saberes médicos.

PALAVRAS-CHAVE: espaço médico; leprosário; saberes médicos.

\section{ABSTRACT:}

This article discusses how the construction of the leprosarium São Francisco de Assis, took place in Natal during the first three decades of the twenty century. We aim to analyze the medical debates on the disease, observing how they influenced the construction, and to discuss how the isolation took place. I used the medical speeches publiched in the main newpapers of the city, and in specialized magazines; and the messagens of the Presidents of State read in the Legislative Assembly. We based our analysis on Certeau's ideas, thus, we understand the leprosarium as a bult space that gained meaning from the speeches and medical knowledge proclaimed.

KEYWORDS: Space medical; leprosarium; medical knowledge.

\footnotetext{
1 Mestre em História pela Universidade Federal do Rio Grande do Norte. Currículo Lattes: http:/ /lattes.cnpq.br/2306196049080297. Endereço de e-mail: isinha_cris@yahoo.com.br.
} 
No Brasil, as epidemias foram tema de debates científicos e de implantação de políticas sanitárias de profilaxia em diferentes temporalidades. Entre as enfermidades que assolaram o território brasileiro podemos citar a malária, a varíola, a sífilis, a gripe espanhola, a hanseníase, a dengue, entre outras. Cada epidemia possui características específicas - agente patológico, forma de contágio, tempo de incubação no corpo humano, sintomas, conhecimento científico sobre a moléstia, tempo histórico em que ocorreu - que mobilizam discursos e ações profiláticas próprias. A pandemia causada pela família de vírus Coronavírus tem evidenciado a relação estabelecida entre os saberes médicos e a organização do espaço da cidade.

Para conter o surto epidêmico e a propagação do vírus, médicos e cientistas orientaram o isolamento social dos indivíduos e a prática da quarentena. Essa orientação causou vários debates entre parcelas da sociedade e a classe política, foram significativas as discussões travadas sobre o isolamento social dos indivíduos. Ao voltarmos o nosso olhar para o passado vemos que o isolamento dos indivíduos já foi utilizado para tratar algumas morbidades, como a gripe espanhola, a varíola, a lepra, entre outras. É importante deixar claro que o isolamento praticado durante o século XIX e em algumas décadas do século XX retirava os doentes do convívio social e os asilava em espaços médicos específicos.

A criação de espaços médicos especializados com a finalidade de isolar os doentes foi a prática profilática utilizada para combater a lepra ${ }^{2}$ no Brasil. Seguindo as orientações nacionais, o Rio Grande do Norte edificou, a partir de 1926, o Leprosário São Francisco de Assis, com a finalidade de asilar todos os doentes do mal de Hansen identificados no Estado. Assim, questionamos como ocorreu o processo de edificação do Leprosário São Francisco de Assis durante as duas primeiras décadas do século XX. O nosso estudo possui como recorte temporal o período de 1915 a 1929. A escolha de 1915 está relacionada com a criação da Comissão de Profilaxia da Lepra, órgão criado para discutir e deliberar sobre as formas de combate à lepra no

\footnotetext{
2 Ao longo deste artigo, usaremos os termos "lepra" e "leproso", por serem mais apropriados ao recorte temporal discutido.
} 


\section{Espacialidades}

Brasil. Por meio dessa comissão foram instituídas as diretrizes nacionais de profilaxia da Lepra a serem seguidas em todos os estados. E a opção por 1929 foi realizada devido à inauguração oficial do Leprosário São Francisco de Assis, espaço médico que simbolizava o cuidado dos poderes públicos com a saúde da cidade e com os preceitos modernos.

Ao analisar a construção do isolamento potiguar, é importante destacar que compreendemos o espaço como uma produção cultural, que ganha significado a partir das práticas instituídas e das simbologias construídas pelos indivíduos. (CERTEAU, 2008). Assim, o Leprosário São Francisco de Assis foi construído a partir dos discursos proclamados pelos saberes médicos e pelos poderes públicos, discursos esses que exaltavam a criação de uma sociedade saudável.

A partir do século XX, com o advento da República, as transformações no campo científico e o crescimento das ideias higienistas, instaurou-se no Brasil a busca pela criação de um homem ideal, republicano e moderno (OLIVEIRA, 2003). Uma série de ações foram realizadas para medicalizar as práticas cotidianas da população e os espaços que existiam na cidade. Assim, o saber médico passou a interferir em diferentes setores da sociedade, estabelecendo novas maneiras de lidar com os doentes e com as doenças.

Nesse sentido, era necessário excluir da cidade todos os elementos que colocavam em risco a formação de uma cidade saudável. Para isso, criaram espaços médicos especializados para recolher e isolar todos os indivíduos que colocavam em risco a saúde da cidade, como asilos, isolamentos, preventórios e leprosários.

A construção do Leprosário São Francisco de Assis se inscreve dentro das ideias de modernidade implantadas no Brasil, que inseriam as doenças como elementos que pudessem prejudicar a formação da nova sociedade que se construía. O discurso proferido pelo saber médico foi incorporado pelo poder público e interferiu em várias instituições, reorganizou espaços médicos existentes na cidade e criou novos espaços médicos especializados. Assim, podemos afirmar que novas 
relações foram instituídas entre saber médico, poder governamental e sociedade, novas práticas foram instituídas, criou-se uma nova cultura médica e política. (BERSTEIN, 1997).

É a partir desses elementos que analisamos os discursos médicos realizados dentro da Comissão de Profilaxia da Lepra veiculados em jornais ${ }^{3}$ e na revista médica especializada Brazil-médico. A partir do estudo dessas fontes buscamos compreender o que os médicos conheciam sobre a enfermidade e quais os seus posicionamentos sobre o isolamento e de que maneira esses discursos influenciaram na construção do leprosário potiguar. Também analisamos os discursos proferidos pelos Presidentes de Estado $^{4}$ no período estudado, buscando compreender o significado que o combate à lepra e a construção do leprosário adquiriram dentro das políticas públicas sanitárias no Estado do Rio Grande do Norte. Por fim, analisamos os jornais que circulavam na cidade, observando como eles incorporaram o discurso oficial e como os leprosos eram retratados.

A lepra - que pode ser definida como uma doença crônica, infectocontagiosa, causada pela bactéria mycobacterium leprae $e^{5}$ foi inserida durante as primeiras décadas do século XX entre as morbidades que necessitavam ser combatidas no território nacional. No entanto, o saber médico sobre essa morbidade era restrito, sobretudo no que diz respeito a sua hereditariedade, a transmissibilidade e o processo de cura. Vários debates e estudos foram realizados por cientistas e médicos buscando maneiras eficientes de tratar o mal de Hansen. Sem respostas instantâneas, o saber médico utilizou como profilaxia o isolamento compulsório dos doentes em instituições apropriadas para esse fim, os leprosários e as colônias agrícolas.

\footnotetext{
${ }^{3} \mathrm{O}$ nosso estudo priorizou a análise dos jornais que circularam na cidade do Rio de Janeiro, local onde se encontravam as principais associações médicas e científicas do período.

${ }^{4}$ Para este estudo analisamos os discursos de duas legislaturas, a saber: José Augusto de Medeiros e Juvenal Lamartine, Presidentes de Estado durante o período de edificação e inauguração do Leprosário São Francisco de Assis.

${ }^{5}$ Bactéria causadora da lepra, descoberta em 1874 pelo médico norueguês Gerhard Henrick Armauer Hansen.
} 
As ações de profilaxia da lepra estavam inseridas em uma política nacional de medicalização da cidade, da criação de um homem civilizado. A partir do século XX, a saúde da população deixava de ser uma questão individual para se transformar em uma questão coletiva, de formação da identidade nacional. O processo de industrialização, a crescente urbanização e o crescimento populacional produziram uma sociedade onde as doenças (epidemias) constituíam-se em elos de interdependência social. A doença, antes vista como problema individual, passou a ser julgada como problema coletivo e, como tal, passível das ações de políticas públicas nacionais. (HOCHMAN, 1998). As intervenções sanitárias implementadas nesse período tinham como base impedir o contato do homem com o micróbio, o indivíduo doente com o indivíduo saudável, para isso o discurso médico criou uma série de medidas direcionadas para a educação dos hábitos coletivos e individuais. O micróbio e a possibilidade de contágio tornavam todos os membros da sociedade indissociáveis. Assim, a preocupação com as doenças (os doentes) estava baseada na ameaça que esses portadores pudessem causar a saúde da sociedade.

Com essa nova visão sobre a saúde coletiva do país, a lepra passou a ser tema das preocupações médicas e ações sistemáticas do governo brasileiro e do governo do Rio Grande do Norte, com estudos de caso, testagem de novos medicamentos, notificação dos suspeitos, censos estatísticos. A partir desses elementos e do aumento significativo dos casos de lepra notificados em diversos estados brasileiros, a epidemia passou a exigir uma política nacional para o seu combate. (CABRAL, 2013). Essas ações consistiram em dois procedimentos: a vigilância dos casos suspeitos e o isolamento dos doentes.

No Rio Grande do Norte, as ações de profilaxia da lepra se concentraram na vigilância dos casos suspeitos nos postos de Saneamento Rural e no isolamento dos doentes no Leprosário São Francisco de Assis. Ao investigar as condições sanitárias e higiênicas do Estado, verifiquei que a lepra não estava entre as moléstias historiadas que atingiam fortemente a população. Os problemas sanitários mais corriqueiros eram as doenças do aparelho digestivo, febre tifoide, febre amarela, a mortalidade 
infantil, entre outras. Apesar dessa ausência de um elevado registro de pessoas contaminadas com o bacilo de Hansen, existiu no Rio Grande do Norte, um conjunto de ações direcionadas para o combate à lepra, entre elas a edificação do Leprosário São Francisco de Assis.

Assim, no ano de 1926, iniciaram o isolamento dos primeiros grupos de leprosos nos antigos pavilhões do Isolamento São Roque. Essa edificação se localizava a seis quilômetros do centro da cidade, longe de áreas alagadas e com árvores frutíferas. O isolamento seguia todas as orientações higiênicas estabelecidas pelas diretrizes estabelecidas pela Comissão de Profilaxia da Lepra para receber os morféticos presentes no Estado. Os debates e as propostas deliberadas pela Comissão de Profilaxia da Lepra foram a base do projeto estatal de combate a lepra. Assim, é importante retratar os debates e as ideias médicas que circularam na Comissão de Profilaxia da Lepra sobre a profilaxia da lepra.

Parcelas da sociedade passaram a debater como ocorreria o isolamento dos doentes. O debate sobre o processo de isolamento perdurou até a década de 1930 e contou, basicamente, com duas posições distintas. A primeira posição defendia a reclusão em pequenas colônias e na própria residência do doente, já a segunda corrente defendia o isolamento compulsório de todos os casos notificados em leprosários ou colônias agrícolas. A segunda corrente tornou-se hegemônica no Brasil entre os participantes da Comissão de Profilaxia da Lepra, grupo responsável por estabelecer diretrizes de profilaxia da doença.

A Comissão de Profilaxia da Lepra, instaurada em 1915, foi o organismo criado por médicos e líderes políticos com o objetivo de discutir e elaborar diretrizes de combate ao mal de Hansen. Essa comissão - idealizada por Belmiro Valverde, leprologista do Hospital de Lázaros no Rio de Janeiro, e Juliano Moreira, professor da Faculdade de Medicina - atuou nos anos de 1915 a 1919 e foi o centro dos debates sobre a lepra no Brasil. A comissão era composta por vários médicos que representavam diferentes instituições científicas do país, a saber: Paulo da Silva Araújo, Henrique de Beaurepaire Rohan Aragão (membros da Associação Médico- 
Cirúrgica); Emílio Gomes, Alfredo Porto e Henrique Autran (membros da Academia Nacional de Medicina); Eduardo Rabello, Werneck Machado e Guedes de Mello (membros da Sociedade de Medicina e Cirurgia); Fernando Terra, Juliano Moreira e Adolpho Lutz (membros da Sociedade Brasileira de Dermatologia). (BENCHIMOL, 2004).

As temáticas debatidas nessa comissão eram de diferentes naturezas: a lepra e o casamento; lepra e profissão; lepra e imigração; lepra e transmissão; lepra e profilaxia, entre outras. Foi a partir do debate realizado por esse grupo de médicos que o mal de Hansen passou a ser entendido como um grande mal nacional que precisava ser combatido e exterminado do Brasil. Para entender a prática do isolamento compulsório dos leprosos e a criação do Leprosário São Francisco de Assis é necessário observar as ideias defendidas pelos membros da comissão, especificamente, sobre a transmissão e a profilaxia dessa moléstia.

Os médicos Juliano Moreira e Fernando Terra defendiam a ideia de que a dificuldade de cultivar o bacilo e, consequentemente, o desconhecimento sobre a sua forma de transmissão, eram fatores decisivos para a proliferação da doença. Segundo os médicos, as pesquisas desenvolvidas, naquela conjuntura, sobre a bactéria, demonstravam que o organismo humano hospedava o bacilo da lepra, tornando-se, assim, o principal responsável pela transmissão da doença. Apesar de saberem que o homem doente era o principal transmissor da bactéria, existiam muitas dúvidas sobre como se dava o contágio entre os indivíduos.

No relatório escrito pelos médicos Fernando Terra e Juliano Moreira apresentado à Comissão de Profilaxia da Lepra, veiculado na revista Braz̧il-Médico de 24 de agosto de 1918, as dúvidas sobre as formas de transmissão da lepra ficaram evidentes. Eles afirmavam: "A primeira dificuldade que surge é saber o momento em que o germe adquire a necessária virulência, para agir no máximo potencial, ou pelo menos o instante propício para a sua transmissibilidade”. (BRAZIL-MEDICO, 1918, p. 265). 


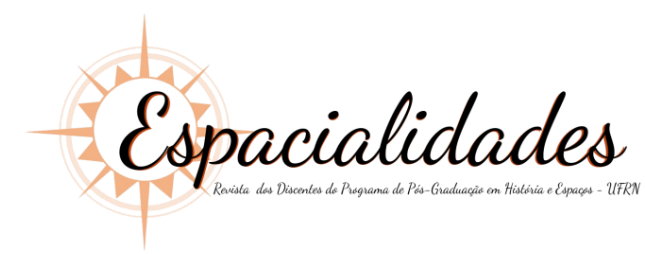

Além das dúvidas sobre o momento que ocorria a transmissão da bactéria, os médicos também tinham dúvidas sobre vários outros aspectos, como: o papel das lesões presentes na pele no processo de contágio; a importância dos períodos febris no processo de transmissão; os estágios da doença no organismo humano; o elo entre os mosquitos sugadores e a transmissibilidade da lepra. Essas dúvidas são retratadas no relatório apresentado pelos dois médicos supracitados à Comissão de Profilaxia da Lepra.

\begin{abstract}
Acreditam leprólogos de vulto que o doente só se torna perigoso para os que se lhe avizinham durante um surto febril. Nessas condições, os bacilos, veiculados em grandes levas pela torrente circulatória, aproximando-se da superfície do organismo facilmente são apreendidos por insetos sugadores. Entretanto, provado que seja esse o mecanismo de transporte do gérmen, não se pode colocar à margem o perigo da emissão dos bacilos nas lesões abertas, fora de uma fase de hipertermia. (BRAZILMEDICO, 1918, p. 265).
\end{abstract}

Diante das dúvidas sobre a bactéria e dos debates realizados entre os médicos, duas teorias sobre as formas de transmissão da lepra ganharam destaque: a transmissão através de mosquitos sugadores e o contágio direto entre os seres humanos.

Entre os principais defensores da teoria da transmissão da lepra através de mosquitos sugadores estava Adolph Lutz, médico e membro do Instituto Osvaldo Cruz. Segundo o médico, a lepra era transmitida por intermédio de mosquitos sugadores nos períodos febris, como ocorria com a malária e a febre amarela. As teorias de Lutz sobre a transmissibilidade da lepra se baseavam nos seus estudos realizados em alguns países da Europa. Para ele, os números reduzidos de notificação de novos casos do mal de Hansen em países europeus ocorriam devido à ausência de mosquitos transmissores nesse território, entre eles, o culex fatigans.

Apoiador das ideias de Adolph Lutz, o médico e membro do Instituto Oswaldo Cruz, Henrique Aragão, corroborou esse ponto de vista e afirmou na comissão: "O que faz supor que os mosquitos sejam transmissores da lepra é o fato da moléstia se propagar onde eles existem, tornando-se absolutamente inócua na ausência de tais insetos.” (BRAZIL-MEDICO, 1924, p. 234). 
Adolph Lutz também defendia que as lesões na pele dos leprosos não eram fontes de contágio. Segundo o médico, as mucosas e a pele ulcerada liberavam grande quantidade de bacilos da Hansen, no entanto esses bacilos perdiam vitalidade no ambiente. Assim, para ele: "Se os bacilos fossem todos vivos e capazes de infectar, diretamente, as causas de contágio deviam ser abundantíssimas, o que não se dá. Deviam também ser observados em toda a parte.” (BECHIMOL, 2004, p.88).

As ideias defendidas por Lutz contrariavam os defensores da teoria contagionista. Para esses médicos, as secreções das úlceras e as mucosidades nasais eram as principais formas de liberação dos bacilos causadores da lepra. Entre os defensores dessa teoria estava o médico Belmiro Valverde. Em matéria intitulada “Transmissibilidade da Lepra”, veiculada pela revista Brazil-Médico de 01 de outubro de 1922, o médico evidenciou a presença das diferentes teorias sobre a transmissibilidade da lepra e retratou os membros do grupo opositor como "cientistas feridos por observações”. (BRAZIL-MEDICO, 1922, p. 179). Esses médicos foram apresentados como cientistas que não seguiam os métodos científicos propagados pelo período, por exemplo, dados estatísticos e provas materiais que comprovassem as suas teorias. A ausência de provas científicas sobre a teoria da transmissão da lepra era a crítica mais apontada por Belmiro Valverde às ideias de Adolph Lutz.

$\mathrm{Na}$ Conferência Americana de Lepra realizada no Rio de Janeiro, em outubro de 1922, Belmiro Valverde defendeu a teoria contagionista e criticou fortemente as ideias defendidas por Lutz e os que comungavam das suas convicções.

\footnotetext{
Entretanto, os que supõem a lepra transmiti-se por vinculação indireta são dogmáticos, como sucede entre nós com o Dr. Adolpho Lutz, que apesar de se ocupar desses assuntos há 40 anos, ainda não pôde trazer a mais ligeira documentação demonstradora do acerto de suas ideias. (JORNAL DO COMMERCIO, 1922, p. 4).
}

Diante das divergências sobre a forma de transmissão da enfermidade, a sua profilaxia também foi tema de debates e controvérsias. O grupo que seguia as ideias de Adolph Lutz criticava o isolamento compulsório dos doentes como a medida mais eficaz para o combate à bactéria. Para esse grupo de médicos a expulsão dos doentes 
do seio da sociedade era vista como desumana, incoerente e pouco eficaz. (BELCHIMOL, 2004). O médico Henrique Aragão, nos debates da Comissão de Profilaxia da Lepra, afirmou que o leproso na França vivia em completa liberdade e não transmitia o seu mal para outros indivíduos. (BRAZIL-MEDICO, 1924).

Já os médicos Eduardo Rabello e Oscar da Silva Araújo, seguidores da teoria contagionista, defendiam que a profilaxia da lepra deveria ser realizada com o isolamento dos doentes em colônias agrícolas e não deveria ser permitido o isolamento domiciliar. Para esse médico, os edifícios precisariam ser instalados em uma geografia específica, seguindo os preceitos higiênicos. Em matéria publicada no jornal Correio da Manhã em 14 de agosto de 1920, o médico Eduardo Rabello afirmou que o isolamento domiciliar consiste em um grande erro, pois contraria os preceitos da higiene moderna. Ele declarou: "o isolamento em domicílio é uma providência que a higiene moderna só tolera para as doenças agudas, de curta duração, condenando em absoluto nas doenças crônicas". (CORREIO DA MANHÃ, 1920, p. 3).

Diante das teorias discutidas entre os médicos e cientistas, a Comissão de Profilaxia da Lepra entendeu que as mucosas nasais e as úlceras presentes na pele eram as principais formas de transmissão da lepra entre os indivíduos. A profilaxia dessa moléstia deveria ser baseada no isolamento obrigatório dos leprosos, sem distinção de classe ou indivíduo, sendo o Estado responsável por criar uma rede de instituições que acolha os leprosos, como demonstrou a matéria veiculada na revista Braz̧il-Médico de 18 de dezembro de 1919. Na seção Associações médicas, o médico Emílio Gomes transcreveu as sugestões da Comissão de Profilaxia da Lepra discutidas na sessão de 23 de outubro da Academia Nacional de Medicina. Ele retratou:

I. O isolamento dos leprosos, base racional da profilaxia da lepra, deve ser obrigatório, sem distinção de classe ou de indivíduo. (...) III. Para os doentes necessitados capazes de trabalho, para os indigentes, invalidados pela moléstia, se fará o isolamento em lugares destinados a sua concentração: a) serão fundadas, para os primeiros, vilas e colônias agrícolas, situadas em local salubre e adequado, onde receberão completa assistência do Estado, devendo exercer as respectivas atividades; b) essas colônias serão providas de instalações apropriadas ao isolamento voluntário de abastados, mediante a retribuição pecuniária necessária. (BRAZIL-MEDICO, 1919, p. 394). 


\section{Espacialidades}

A comissão também aconselhou várias outras ações e medidas para combater o mal de Hansen, a saber: a) Os casamentos entre os leprosos deveriam ser evitados, bem como a descendência desses indivíduos deveria ser fiscalizada pela vigilância médica e o Estado deveria criar espaços especiais nos asilos para receber os filhos desses leprosos; b) Permitia a anulação do casamento ou o desquite se comprovasse a existência da lepra em uma das partes; c) O leproso ficaria proibido de exercer qualquer atividade profissional entre a população sadia ou mesmo manipular qualquer produto agrícola ou industrial. (BRAZIL-MEDICO, 1919).

A partir das ideias defendidas pela Comissão de Profilaxia da Lepra, foi instituído o Decreto n ${ }^{\circ} 16.300$, de 31 de dezembro de 1923, assinado por João Luís, Ministro da Justiça do governo Artur Bernardes. Esse decreto determinou a obrigatoriedade em território nacional do isolamento dos leprosos em colônias ou no próprio domić́lio.

A partir das diretrizes nacionais de combate à lepra, o Rio Grande do Norte, através dos postos de Saneamento Rural e da criação do Serviço de Profilaxia da Lepra, este último instaurado no ano de 1924, no mandato de José Augusto Bezerra, iniciaram o processo de notificação dos indivíduos portadores do mal de Hansen e os seus comunicantes. Entre os anos de 1923 a 1925, o Serviço de profilaxia da Lepra notificou no Rio Grande do Norte 109 leprosos, dos quais 13 faleceram e 91 doentes permaneceram em tratamento. O tratamento desses doentes consistia na vigilância do enfermo, dos seus comunicantes e na utilização de alguns remédios, como o óleo de chaulmoogra ${ }^{6}$.

A partir dos números de leprosos conhecidos e das ideias científicas proclamadas nesse período, circularam no Estado discursos defendendo a

\footnotetext{
${ }^{6}$ Óleo volátil obtido das sementes de várias plantas originárias da Índia. As plantas conhecidas pela designação de chaulmoogras pertencem à família das Flacourtiáceas. Para mais informações, ler: SANTOS, Fernando Sérgio Dumas dos et al. O óleo de chaulmoogra como conhecimento científico: a construção de uma terapêutica antileprótica. História, Ciências, Saúde - Manguinhos, Rio de Janeiro, v.15, n.1, p.29-47, jan.-mar. 2008.
} 
necessidade de construção de um isolamento para os acometidos pelo mal de Hansen. Nesses discursos os doentes eram retratados como "perigosos" para a saúde da cidade. Entre os defensores dessa prática, podemos citar o inspetor de saúde, Octávio Varella. Ao apresentar as medidas de higiene no jornal $A$ Imprensa, em seis de maio de 1923, o inspetor evidencia a sua preocupação com os casos de lepra comprovados no Estado e a necessidade de construção de um pequeno leprosário para receber esses doentes. Na mesma matéria, afirmou, "essencialmente contaminável a lepra constitui em cada doente um foco de infecção, um núcleo que irradia a desgraça e a morte". (A IMPRENSA, 1923, p. 1).

O jornal $A$ República, no dia 21 de outubro de 1926, em matéria intitulada "O perigo da lepra", informava à população potiguar o perigo que os doentes de lepra representavam para a sociedade e como ocorria a contaminação do bacilo entre os indivíduos doentes e sadios. A matéria reafirmava ser o doente o hospedeiro do bacilo e o principal transmissor do mal por meio das suas secreções nasais: "Existindo em grande quantidade os bacilos de Hansen na mucosa nasal dos morféticos, este fato constitui um grande perigo para aqueles que daquelas infelizes criaturas se avizinham." (A REPÚBLICA, 1926 p. 2). Ainda segundo a matéria, eram os leprosos que propagavam o mal entre a população sadia, sendo indispensável o afastamento desses doentes do convívio social, mesmo entre pais e familiares. Os discursos que circularam na cidade se assemelharam com os discursos que eram proferidos pelos participantes da Comissão de Profilaxia da Lepra, os leprosos eram vistos como um grande mal que precisavam ser excluídos dos espaços comuns da cidade e que todos aqueles que conviviam com morféticos poderiam ser contaminados pela bactéria.

Nos discursos oficiais a necessidade de criação de um espaço para asilar os leprosos foi registrada no ano de 1925. O Presidente do Estado José Augusto de Medeiros afirmou: "O plano da Comissão de Saneamento Rural, há muito traçado, para dar um cunho de eficiência absoluta ao serviço de profilaxia da lepra neste estado consiste na criação de uma colônia de leprosos". (RIO GRANDE DO NORTE, 


\section{Espacialididades}

1925, p. 41). Declarou ainda: "Para evitar a disseminação de moléstia tão terrível, cabe cogitar providências eficazes e prontas". (RIO GRANDE DO NORTE, 1925, p.36).

Segundo o Diretor de Saúde, Manoel Varella Santiago Sobrinho, várias medidas higiênicas eram necessárias para melhorar as condições sanitárias da cidade, entre elas estava a criação de um leprosário. Esse isolamento recolheria no primeiro momento os doentes mais perigosos para a saúde da população, como afirmou o Diretor de Saúde: “A criação de um leprosário, que se destine a receber de preferência os morféticos que, pelo seu estado adiantado de doença e de pobreza, mais perigosos se tornam às populações municipais do Estado”. (RIO GRANDE DO NORTE, 1925, p.37). Segundo o discurso oficial as ações de profilaxia contra lepra eram de caráter de urgência e a criação de um espaço físico adequado para receber os morféticos era a solução mais eficiente.

Sem recursos financeiros disponíveis e diante da necessidade de construção urgente de um espaço adequado para receber os morféticos do Estado, o Diretor de Saúde Pública, Varella Santiago, propôs que inicialmente o isolamento dos leprosos fosse realizado em um espaço pequeno, sem grandes instalações físicas. Para tal fim foi escolhido o antigo Isolamento São Roque. Esse espaço médico foi construído no ano de 1911, no município que correspondia a Macaíba, e tinha o objetivo de isolar os doentes de varíola. Esse isolamento apresentava os principais elementos higiênicos (água encanada, esgoto próprio, estrutura de pavilhões) e geográficos (distante do centro da cidade, com árvores frutíferas, longe de áreas alagadas) defendidos pelas normas higiênicas, pelos preceitos da geografia médica e pela Comissão de Profilaxia da Lepra. Assim, os dois pavilhões do Isolamento São Roque receberam reformas e adequações físicas e foi utilizado para abrigar o primeiro grupo de leprosos isolados no Rio Grande do Norte no ano de 1926. (RIO GRANDE DO NORTE, 1911, p. 11).

Os primeiros internos foram isolados entre julho e outubro no ano de 1926, no total de três doentes: Jorge Friscle, natural da França, internado em vinte de julho de 1926; Bento Gomes de Oliveira, nascido no município de Macaíba, internado em 
quatro de outubro de 1926; O terceiro doente isolado não foi possível identificar durante a produção deste artigo. Após a instalação desse primeiro grupo de doentes nos antigos pavilhões do Isolamento São Roque, várias diretrizes foram traçadas para a construção definitiva do Leprosário São Francisco de Assis. A primeira delas foi a compra do sítio localizado próximo ao isolamento. Esse terreno pertencia ao jovem Rodrigo Ribeiro Resende e, no dia 13 de março de 1926, foi comprado pelo Governo do Estado no valor de seis contos e quinhentos mil réis. Segundo a escritura de compra e venda do sítio, o terreno era cercado e composto de casa de vivenda, árvores frutíferas e outras benfeitorias, possuía todas as características apropriadas para a instalação do isolamento dos morféticos?

Com o local onde funcionaria o isolamento definido e com o primeiro grupo de internos isolados, era necessário continuar a organização da construção. Para iniciar as obras de edificação foi formada a Comissão Central Pró-leprosário. Essa comissão foi formada com o objetivo de angariar recursos para a construção do espaço médico. Dirigida pelo médico Varella Santiago, contou com figuras importantes da política e da administração pública, a saber: Augusto Leopoldo (Vicegovernador do Estado), Waldemar Antunes, Theotônio Freire (Juiz municipal e federal), Felippe Guerra (Procurador Geral do Estado), Monsenhor Alves Landin, Coronel José Lagrega, Coronel João Galvão Filho e Omar O’ Grady (Intendente de Natal). (A REPÚBLICA, 1926). Como evidenciado, a Comissão Central Próleprosário, contou com membros que exerciam ou tinham exercido importantes funções no campo político e econômico do Estado. Para uma tarefa tão importante, no que diz respeito à saúde pública do Estado, esses homens representavam a importância do empreendimento.

Várias ações foram elaboradas pela comissão, dentre as quais podemos destacar festas organizadas por associações beneméritas da capital, sobretudo as organizações religiosas. De acordo com o jornal A República, foram realizados vários

\footnotetext{
7 Informações presentes na escritura pública de compra e venda do terreno, registrada em 13 de março de 1926, no livro 125, translado $1^{\circ}$, folhas 77 a 79, no Primeiro Ofício de Notas.
} 


\section{Espacialididades}

eventos, para arrecadar fundos destinados à construção do Leprosário São Francisco de Assis, entre os anos de 1926 e 1928. Entre os principais grupos que atuaram no financiamento do isolamento dos leprosos, identifiquei três grupos principais, a saber: as alunas da Escola Doméstica, a Congregação Mariana de Moços e a Cruzada Feminina. Entre os principais eventos, o jornal A República, de cinco de agosto de 1926, retratou a coleta de fundos realizada pela Congregação Mariana de Moços em algumas cidades do Estado. (A REPÚBLICA, 1926). Já o jornal O Imparcial, no dia vinte e cinco de janeiro de 1929, com a matéria "Belo gesto da Caravana feminina", noticiou a ação da Cruzada Feminina no município de Ceará-Mirim e a arrecadação dessa organização de dez contos de réis para a construção do isolamento de leprosos. (O IMPARCIAL, 1929).

Todo o trabalho da Comissão Central Pró-Leprosário teve o forte apoio dos jornais e de parte da população, que apresentavam esse espaço como primordial para a manutenção da saúde potiguar.

O leprosário a ser edificado, segundo as ideias do Diretor de Saúde, Varella Santiago, deveria seguir dois elementos principais: o primeiro, permitir o isolamento perfeito dos doentes com a população sadia, por isso a escolha geográfica, longe do centro da cidade e sem áreas alagadas que permitissem a presença de mosquitos sugadores conforme defendia Adolph Lutz. E, segundo, deveria permitir o conforto de todos os internos e os meios de tratamento necessários para conter a enfermidade. Seguindo as ideais do médico Eduardo Rabello, para Varella Santiago, Diretor de Saúde do Estado, somente o isolamento total dos leprosos acabaria com a propagação do mal o Hansen no Estado: "esta é a única fórmula, humana e científica, que poderá resolver o mais sério problema sanitário norte-rio-grandense. (RIO GRANDE DO NORTE, 1924, p. 76). Assim, como pode ser observado, a edificação do Leprosário São Francisco era entendida como a única forma de conter o aumento dos casos de lepra no Estado, era um espaço necessário para o bem coletivo.

Com as doações angariadas pela Comissão Pró-Leprosário e com os recursos estaduais, as obras do isolamento foram iniciadas em 1928. No ano seguinte, 1929 


\section{Espacialididades}

(data oficial da inauguração do leprosário), as instalações foram inauguradas. O primeiro grupo de casas foi entregue no dia 14 de janeiro de 1929, formada por dez habitações, essas construções possuíam boas instalações sanitárias, com piso de mosaico e cozinha. Em cada casa residiam dois ou três leprosos. Dando continuidade à edificação, em 26 de maio de 1929, foi inaugurado um cemitério e mais cinco grupos de casas, cada uma com duas habitações. (BRAZIL-MEDICO,1930, p. 170). Essas casas foram classificadas como casas do tipo B e apresentavam melhores acomodações físicas e sanitárias, e tinham mais conforto para os doentes, como retratou a mensagem do Presidente do Estado lida na Assembleia Legislativa no ano de 1929 (RIO GRANDE DO NORTE, 1929). O último grupo de casas, chamado de tipo C, foi entregue somente em cinco de janeiro de 1930 e era destinado aos casais presentes no isolamento (CARDOSO, 2000).

O Leprosário São Francisco de Assis não construiu todas as suas edificações ao mesmo tempo, o seu conjunto arquitetônico sofreu intervenções em diferentes períodos, até a inauguração oficial, como também recebeu novos conjuntos de casas e serviços durante as décadas 1930 e 1940. O jornal Correio Paulistano, de trinta de abril de 1930, noticiou as novas construções realizadas no isolamento dos leprosos, como instalação de usina elétrica, construção privativa para o abrigo das irmãs de caridade, aparelho de rádio e diversão para os isolados. (CORREIO PAULISTANO, 1930).

Posso inferir que as dependências internas do leprosário só foram finalizadas após 1930. Os internos recolhidos antes desse período, sobretudo durante os anos de 1926 a 1928, foram isolados sem a infraestrutura defendida pelos principais médicos e cientistas. Após as edificações dos grupos de casa e as construções de outros espaços administrativos e de lazer para os internos, o Leprosário São Francisco de Assis se adequou as ideias defendias pela Comissão de Profilaxia da Lepra.

O leprosário foi edificado em grupos de casas, onde os internos dividiam o espaço com outros doentes e as famílias isoladas não eram separadas. Essa forma de isolar os internos diferia de outros isolamentos presentes no Brasil, que tinham a sua 
arquitetura baseada em pavilhões. O Diretor de Saúde, Dr. Manoel Varella Santiago Sobrinho, justificou a utilização desse tipo de edificação: "o Departamento de Saúde tem preferido construir pequenos grupos de casas, ocupadas sempre por um número reduzido de doentes, os quais, por se sentirem assim mais à vontade, melhor suportarão a vida de isolamento" (RIO GRANDE DO NORTE, 1930, p. 68).

O isolamento potiguar contou com a presença de grupos de casas para isolar os leprosos, reconstituindo a configuração de uma cidade. Os dois pavilhões presentes abrigaram os serviços administrativos da instituição. Ainda no sentido de tornar o isolamento uma cidade, com todas as suas características, implantaram-se cemitério, capela, atividades de lazer e algumas atividades manuais. Os internos eram incentivados a trabalhar no interior do isolamento, como se pode observar nesta mensagem do Presidente do Estado: "O diretor do serviço procura sempre dar ocupação aos seus enfermos válidos e essas ocupações consistem, sobretudo na cultura dos terrenos do estabelecimento”. (RIO GRANDE DO NORTE, 1930, p.68). Ainda sobre o trabalho realizado na colônia, o Diretor Varella Santiago, afirmou: "Há uma área para os trabalhos agrícolas onde os que foram homens do campo cultivam como se estivessem nas fazendas". (JORNAL DO BRASIL, 1929, p. 08).

Como apresentado, o modelo de isolamento proposto para o Leprosário São Francisco de Assis seguiu o modelo defendido pelo Departamento Nacional de Saúde, um isolamento que possibilitasse ao doente um convívio prazeroso e agradável aliado aos preceitos da ciência moderna. A arquitetura das casas e dos pavilhões deveria conter os elementos da modernidade urbana: setorização, conforto ambiental (insolação, ventilação), funcionalidade, racionalidade. (CASTRO, 2005). Os serviços presentes nessa instituição hospitalar também deveriam seguir os preceitos modernos, como a presença do abastecimento de água, de esgoto e de luz elétrica, elementos indispensáveis para o convívio sadio do homem republicano.

A partir do que foi exposto, podemos inferir que a construção do isolamento dos doentes de lepra no Rio Grande do Norte fez parte de um movimento nacional 


\section{Espacialidades}

de combate a essa doença. A classe médica e a classe política potiguar seguiram os preceitos nacionais e inseriram o combate à propagação do mal de Hansen no Estado como uma medida urgente e necessária para a manutenção da saúde da cidade.

A construção do isolamento foi inserida como uma das mais urgentes ações a serem realizadas em prol do bem coletivo potiguar, mas o Estado não dispunha de condições financeiras para tal empreendimento sanitário. Assim, o isolamento dos lázaros realizado no Rio Grande do Norte, nos seus primeiros anos, não se efetivou de forma plena e em espaço físico adequado, como foi recomendado pela Comissão de Profilaxia da Lepra. Foi realizado em uma construção adaptada, isolando apenas alguns leprosos, aqueles que ofereciam maior "perigo" à sociedade. Dessa forma, posso afirmar que o isolamento dos doentes foi uma resposta política às novas demandas sanitárias e higiênicas.

O combate à lepra no Estado, bem como a construção do isolamento potiguar (arquitetura e serviços ofertados aos internos), fez parte de uma nova cultura política que inseria os saberes médicos no processo de organização da cidade e na criação de políticas públicas. $\mathrm{O}$ isolamento dos leprosos tinha como princípio inserir o Estado nos novos padrões modernos de atenção à saúde e às doenças.

A partir do século XX os surtos epidêmicos ocorridos no Brasil colocaram em evidência dois elementos: a importância do bem-estar coletivo e a saúde da sociedade em detrimento dos direitos individuais. A prática do isolamento dos doentes em leprosários, asilos, preventórios e colônias se justificava baseada na ideia do bem-estar coletivo, da manutenção de uma cidade saudável e livre de microorganismos que colocassem em risco as pessoas sadias. Seguindo essas ideias proclamadas por cientistas e materializadas pelo poder político, os padrões higiênicos foram normatizados, práticas de cura foram proibidas, hábitos cotidianos foram condenados e vários indivíduos foram retirados das suas casas e dos seus trabalhos para serem asilados em espaços médicos. 
Neste artigo, abordei os saberes médicos debatidos nas principais instituições de pesquisa presentes no país e utilizamos como análise apenas o discurso oficial presente no Estado sobre a construção do Leprosário São Francisco de Assis. A História da Saúde e da Doença, bem como os estudos sobre as diferentes morbidadades que assolaram o Estado, entre elas a lepra, possuem um vasto campo de pesquisa a ser desenvolvido. O objetivo deste trabalho era demonstrar como o plano nacional de combate a lepra e as ideias médicas que circulavam no país foram incorporadas nas políticas públicas de saúde no Rio Grande do Norte.

Posso afirmar que o conhecimento científico e o saber médico interferem na forma como uma sociedade se relaciona com as doenças e os doentes, esse saber constrói discursos, organiza ações de políticas públicas e elabora práticas profiláticas. Contudo, ao analisarmos o combate à lepra efetivado no Brasil, observamos que a ausência de conhecimento científico sobre as doenças e os seus agentes causadores também interfere na forma como a sociedade se relaciona com os seus doentes e estabelece ações de políticas públicas. O isolamento dos morféticos em colônia ou leprosários era justificado tomando por base o alto poder de contágio entre os seres humanos. Os médicos e os cientistas não tinham muitos conhecimentos sobre o agente causador da lepra, nem o seu processo de transmissão. Assim, a falta de conhecimento científico sobre a morbidade, bem como a cultura política e médica presente no início do século XX, estabeleceram o isolamento dos indivíduos portadores desse mal em leprosários.

\section{FONTES}

A IMPRENSA, Natal, 1923.

A REPÚBLICA, Natal, 1926.

BRAZIL-MEDICO, Rio de Janeiro, 1918-1930.

CORREIO PAULISTANO, São Paulo, 1930.

CORREIO DA MANHÃ, Rio de Janeiro, 1920. 
JORNAL DO BRASIL, Rio de Janeiro, 1929.

JORNAL DO COMMERCIO, Rio de Janeiro, 1922.

O IMPARCIAL, Maranhão, 25 de janeiro de 1929.

RIO GRANDE DO NORTE. Mensagem apresentada ao Congresso Legislativo na abertura da segunda sessão da sétima legislatura em 01 de novembro de 1911 pelo governador Alberto Maranhão. Natal: Typ. D’ A Republica, 1911.

RIO GRANDE DO NORTE. Mensagem lida perante o Congresso Legislativo na abertura da primeira sessão da décima segunda legislatura em 01 de novembro de 1924 pelo governador José Augusto Bezerra de Medeiros. Natal: Typ. D’ A Republica, 1924.

RIO GRANDE DO NORTE. Mensagem lida perante o Congresso Legislativo na abertura da segunda sessão da décima segunda legislatura em 01 de novembro de 1924 pelo governador José Augusto Bezerra de Medeiros. Natal: Typ. D’ A Republica, 1925.

RIO GRANDE DO NORTE. Mensagem apresentada pelo Presidente do Estado do Rio Grande do Norte a Assembleia Legislativa e lida na abertura da primeira sessão da décima quarta legislatura, em 01 de outubro de 1928. Natal: Imprensa Oficial do Estado, 1928.

RIO GRANDE DO NORTE. Mensagem apresentada pelo Exmo. Dr. Juvenal Lamartine de Faria Presidente do Estado do Rio Grande do Norte à Assembleia Legislativa por ocasião da abertura da terceira sessão da décima terceira legislatura. Natal: Imprensa Oficial do Estado, 1929.

RIO GRANDE DO NORTE. Mensagem apresentada pelo presidente Juvenal Lamartine de Faria à Assembleia Legislativa por ocasião da abertura da primeira sessão da décima quarta legislatura. Natal: Imprensa Oficial do Estado, 1930.

\section{REFERÊNCIAS}

BENCHIMOL, Jaime; ROMERO SÁ, Magali. (Org.). Adolph Lutz: hanseníase. Rio de Janeiro: Fiocruz, 2004.

BERSTEIN, Sérgio. A cultura política. In: RIOUX, Jean-Pierre; SIRINELLI, JeanFrançois. Para uma história cultural. Lisboa: Estampa, 1997. 
CERTEAU, Michael. A invenção do cotidiano: artes de fazer. Petrópolis: Vozes, 2008.

CABRAL, Dilma. Lepra, medicina e políticas de saúde no Brasil (1894-1934). Rio de Janeiro: FIOCRUZ, 2013.

CARDOSO, Rejane (Coord.). 400 nomes Natal. Natal: Prefeitura Municipal do Natal, 2000. (Coleção Natal 400 anos).

CASTRO, Elizabeth Amorim. O Leprosário São Roque e a modernidade: uma abordagem da hanseníase na perspectiva da relação espaço-tempo. 2005. $100 \mathrm{f}$. Dissertação (Mestrado em Geografia) - Universidade Federal do Paraná, Curitiba, 2005.

HOCHMAN, Gilberto. A era do saneamento: as bases da política de saúde pública no Brasil. São Paulo: Hucitec, 1999.

OLIVEIRA, Iranilson Buriti de. Fora da higiene não há salvação: a disciplinarização do corpo pelo discurso médico no Brasil Republicano. Revista de Humanidades. v. 4, n.7, p. 14-29, fev./mar. 2003. 